\title{
Research
}

Claire Blacklock, Tanya Ali Haj-Hassan and Matthew J Thompson

\section{When and how do GPs record vital signs in children with acute infections?}

\author{
A cross-sectional study
}

\begin{abstract}
Background

NICE recommendations and evidence from ambulatory settings promotes the use of vital signs in identifying serious infections in children. This appears to differ from usual clinical practice where GPs report measuring vital signs infrequently.
\end{abstract}

\section{Aim}

To identify frequency of vital sign

documentation by GPs, in the assessment of children with acute infections in primary care.

\section{Design and setting}

Observational study in 15 general practice surgeries in Oxfordshire and Somerset, UK.

\section{Method}

A standardised proforma was used to extract consultation details including documentation of numerical vital signs, and words or phrases used by the GP in assessing vital signs, for 850 children aged 1 month to 16 years presenting with acute infection.

\section{Results}

Of the children presenting with acute infections $31.6 \%$ had one or more numerical vital signs recorded $(269,31.6 \%)$, however GP recording rate improved if free text proxies were also considered: at least one vital sign was then recorded in over half $(54.1 \%)$ of children. In those with recorded numerical values for vital signs, the most frequent was temperature (210, 24.7\%), followed by heart rate (62,7.3\%), respiratory rate $(58,6.8 \%)$, and capillary refill time $(36,4.2 \%)$. Words or phrases for vital signs were documented infrequently (temperature $17.6 \%$, respiratory rate $14.6 \%$, capillary refill time $12.5 \%$, and heart rate $0.5 \%$ ), Text relating to global assessment was documented in $313 / 850(36.8 \%)$ of consultations.

\section{Conclusion}

GPs record vital signs using words and phrases as well as numerical methods, although overall documentation of vital signs is infrequent in children presenting with acute infections.

\section{Keywords}

child; infection; general practice; physical examination; primary health care.

\section{INTRODUCTION}

The 2007 National Institute of Health and Clinical Excellence (NICE) guideline on the management of feverish illness in young children recommended that UK clinicians routinely measure temperature, heart rate $(H R)$, respiratory rate, and capillary refill time (CRT) in feverish children aged $<5$ years. ${ }^{1}$ There is ongoing research into the diagnostic value of vital signs in children in primary care settings, ${ }^{2}$ however evidence from ambulatory settings has identified signs such as RR as useful in tools in assessing children with serious infections. ${ }^{3-7}$ Many such studies have been conducted in populations where the risk of serious infection is much higher (for example, emergency departments) than typically found in UK general practice.

A survey of UK GPs prior to the NICE guideline found that vital signs were measured in only a minority of children; for example, GPs measured temperature at least once a week in $54 \%$ of children, pulse rate in $21 \%$, and RR in $17 \% .{ }^{8}$ As well as comparing actual measurement to selfreport, publication of the NICE guideline in 2007 therefore presented an opportunity to assess whether GPs had changed their practice. The study speculated that UK GPs might not routinely measure numerical vital signs in children with acute infections because they consider other methods of assessment more useful or quicker.?

As part of a recent study of 'red flag' symptoms in children with acute illnesses in primary care, the study undertook a

C Blacklock, MRCP, MRCGP, DTM\&H, clinica researcher, GP; T Ali Haj-Hassan, BA, BSc, MSc, BMBCh, medical student; MJ Thompson, MPH, MRCGP, DTM\&H, DPhil, senior clinical scientist, GP. Department of Primary Care Health Sciences, University of Oxford, Oxford.

\section{Address for correspondence}

Matthew J Thompson, Department of Primary

Care Health Sciences, University of Oxford, 23-38 Hythe Bridge Street, Oxford, OX1 2ET. large cross sectional analysis of children presenting to GP surgeries in two areas of England.${ }^{10}$ As an additional component of the study the study examined the GP records of all children presenting with acute infections (febrile and non-febrile). This study reports on the frequency with which GPs recorded vital signs in this group of children, to compare with previous self-report, NICE recommendations, ${ }^{1}$ and also to determine whether GPs use alternative methods such as non-numeric text to indicate the normality or otherwise of vital signs.

\section{METHOD}

\section{Data collection}

Children between 1 month and 16 years presenting in primary care with acute illness were recruited from general practice surgeries in Oxfordshire and Somerset, between June 2007 and July 2009 (20 sampling periods of 1 week duration). The methods have been previously presented in detail. ${ }^{10}$ In summary, children were recruited at point of presentation for an appointment with a GP. Children with a final diagnosis inconsistent with an acute infection ffor example, minor trauma, atopic eczema, asthma, allergic rhinitis, or infantile colic), those with obvious minor focal infections of the skin in whom there were no systemic symptoms or concern about systemic illness (for example, paronychia, local fungal infections, or verrucae), and those in whom there was insufficient information to determine a diagnosis were excluded. In the cohort analysed for the

E-mail: matthew.thompsonaphc.ox.ac.uk Submitted: 1 December 2011; Editor's response: 25 January 2012; final acceptance: 9 May 2012.

\section{CBritish Journal of General Practice}

This is the full-length article (published online 1 Oct 2012) of an abridged version published in print. Cite this article as: Br J Gen Pract 2012; DOI: 10.3399/bjgp12X656810 


\section{How this fits in}

Current guidelines recommend measurement of vital signs in children with acute infections however self-reported frequency of vital signs measurement has been poor among GPs. Numerical documentation of vital signs by GPs, in children presenting with acute infections, was poor, $31.6 \%$ of children had one or more numerical vital sign documented. Some GPs recorded words or phrases relating to vital signs instead of a numerical value, increasing the overall proportion of children with vital signs documented to $54.1 \%$.Global assessment was documented in just one-third of consultations, even though this has been found to be highly predictive of serious infections.

present study, the study did not exclude or include participants on the basis of a history or presence of fever. Parents completed a symptoms questionnaire on arrival, and GPs recorded their consultation as per usual practice. GPs were aware that the study was being conducted, but were unaware that the frequency of vital sign recording would be analysed

\section{Vital signs recording}

Data were extracted from each child's medical records by a member of the research team including consultation documentation and final diagnosis, as well as any urgent hospital referral on the day of consultation or in the subsequent 2 weeks. A standardised proforma was used to extract consultation details, including documentation of $H R$, RR, temperature, CRT and also pulse oximetry. In addition the study searched for words or phrases used by the GP to describe the child which

Table 1. Diagnoses of 850 children seen by GPs with symptoms of acute infection

\begin{tabular}{lc} 
Diagnosis & Frequency \\
\hline Upper respiratory tract infection & $494(58.1)$ \\
\hline Non-specific viral illness & $118(13.9)$ \\
\hline Bronchiolitis/viral wheeze/lower respiratory tract infection/pneumonia & $77(9.1)$ \\
\hline Cellulitis & $42(4.9)$ \\
\hline Rash/other skin infection & $39(4.6)$ \\
\hline Gastroenteritis & $36(4.2)$ \\
\hline Urinary tract infection & $23(2.7)$ \\
\hline Other & $21(2.5)$ \\
\hline
\end{tabular}

could be related to global assessment or assessment of vital signs. These were recorded verbatim by hand.

\section{Analysis}

Data were entered into a Microsoft ${ }^{\circledR}$ Office Access (2003) database. The study determined the frequency of recording of each vital sign in all children. Two researchers blinded to final diagnosis and GP identifiers, identified and independently coded free text that related to vital signs. The study included all words and phrases used by GPs that were considered by the researchers to be a non-numerical proxy of vital signs measurement (that is, temperature, HR, RR, and CRT), or that related to the GP's global assessment of the child. The study excluded words or phrases referring to examination findings not considered by the researchers to be a proxy of either vital signs or global assessment. In the example of non-numerical proxy for RR, the study did not include words and phrases referring to non-specific systems examination (for example, 'chest normal'), or those referring to the presence of cough, percussion or auscultatory findings relating to air entry or added sounds.

Terms and phrases relating to each vital sign were compared between the two researchers and a final agreed list for each of the vital signs was developed. Any disagreements were resolved by consensus with a third researcher. The presence or absence of recording of non-numerical vital signs was independently coded, and then agreed for each child between two researchers. Inter-researcher agreement was assessed by calculating kappa.

The study used SPSS for Windows (version 14.0) to analyse frequency of vital signs recording, both numerical and nonnumerical terms. The study performed subgroup analyses by age of child $l<1$ year, 1-4 years, 5-14 years) and whether or not an infection was serious /defined as referral or admission to hospital within 2 weeks of the initial consultation). The study also compared frequency of numerical vital sign documentation and non-numeric text recording of vital signs. The study used $\chi^{2}$, or Fishers exact test when expected frequencies were $<5$, to compare subgroups in the analysis.

\section{RESULTS}

\section{Study sample}

The study recruited a total of 1207 children from 15 GP surgeries in Oxfordshire and Somerset. The study excluded 341 $(28.3 \%)$ children without a final diagnosis 


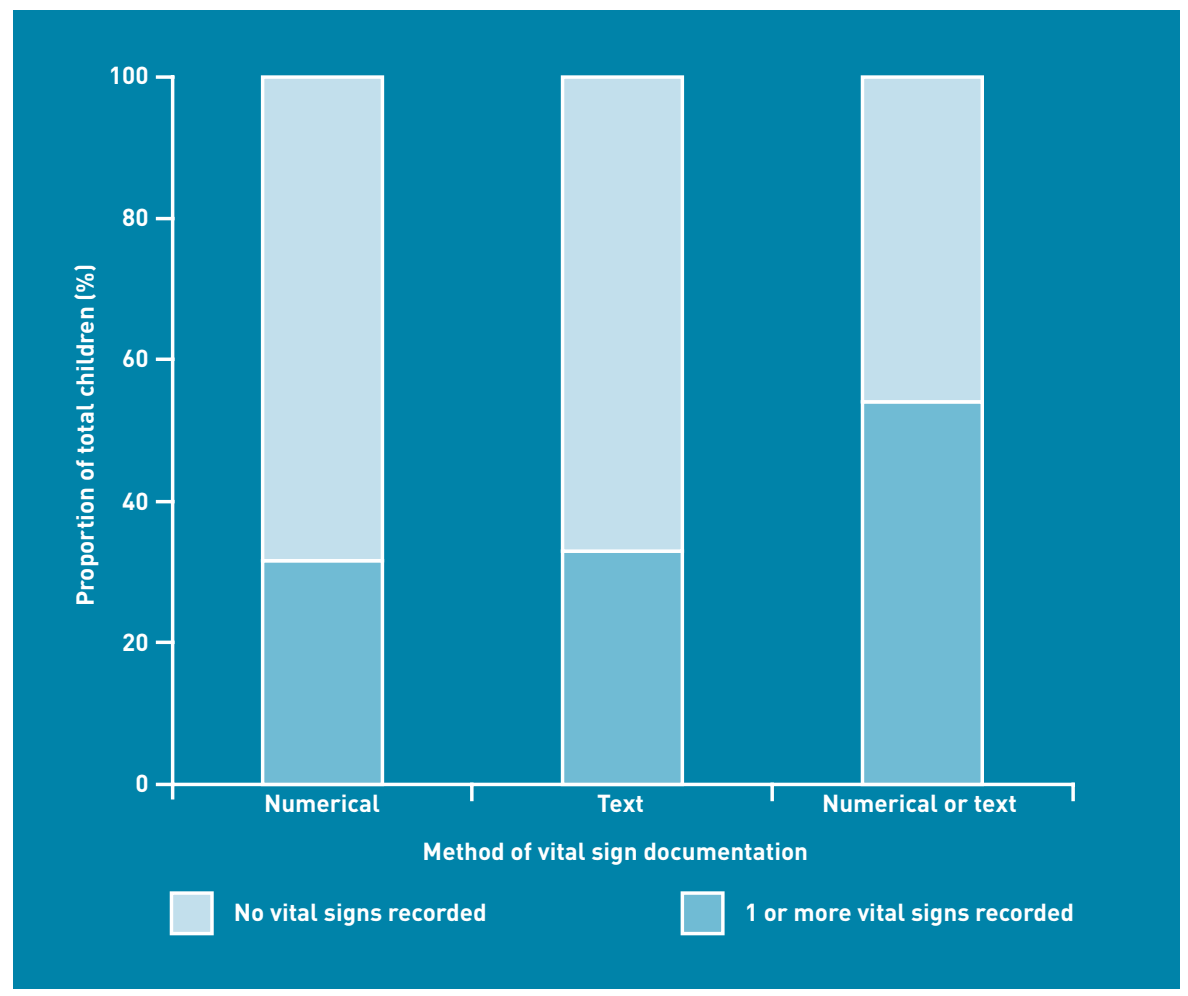

Figure 1. Proportion of children in whom one or more vital sign was recorded at consultation. children had at least one vital sign recorded by the GP (54.1\%). The majority of children ( $n=581,68.4 \%$ ) did not have any numerical vital signs values recorded however, and a further $22.0 \%$ ( $n=204$ ) had just one numerical vital sign value recorded. Free text was used to record at least one vital sign in one-third of children (33.1\%).

\section{Frequency of documentation of individual vital signs}

The most frequently recorded numerical vital sign was temperature ( $n=210,24.7 \%)$, followed by HR ( $n=62,7.3 \%)$, RR ( $n=58$, $6.8 \%$ ), and CRT/circulation ( $n=36,4.2 \%$ ). The most frequent text recorded proxy was also temperature ( $n=150,17.6 \%)$, followed by $\operatorname{RR}(n=124,14.6 \%)$, CRT/ circulation ( $n=106,12.5 \%)$, and finally HR ( $n=4,0.5 \%$ ). When free text relating to vital signs was added to numerical recording. frequency of documentation of individual vital signs increased from $24.7 \%$ to $41.1 \%$ for temperature $(n=349)$, from $6.8 \%$ to $18.6 \%$ for RR ( $n=3158$ ), from $4.2 \%$ to $15.9 \%$ for CRT/circulation ( $n=3135)$, but changed little for HR (from $7.3 \%$ to $7.6 \%(n=65)$ (Figure 2).

Temperature, RR and CRT were recorded using numbers or text significantly more often in children under 5 years, compared to those 5-16 years of age (temperature $45.1 \%$ versus $35.1 \%, P=0.004$; RR $25.5 \%$ versus $8.4 \%, P<0.001$; CRT $23.0 \%$ versus $5.5 \%, P<0.001)$. RR and CRT were also reported more frequently in infants $(<1$ year) compared to children aged $>1$ year $(36.9 \%$ versus $15.5 \%, P<0.001$ and $32.8 \%$ versus $13.0 \%, P<0.001$ respectively). There was no significant difference in recorded frequency of HR by age group, and this was the least frequently recorded vital sign across all groups (Figure 2). Fourteen of the 23 children (60.9\%) with serious infections had at least one numerical or text proxy for vital sign recorded by the GP, compared to 446 of the 827 (53.9\%) of those children who did not have serious infections, however numbers were small.

\section{Frequency of global assessment documentation}

GPs documented their global assessment of the child in $313 / 850$ (36.8\%) of consultations (Figure 3), using a wide range of phrases (Appendix 2). These broadly grouped in parallel to the NICE feverish child traffic light system"1 and the Yale Observation Scale:11 quality of cry, alertness/ state variation, response to social cues/reaction to parent stimulation, 'gut feeling' and tone. Agreement for recording of global assessment between the two researchers 

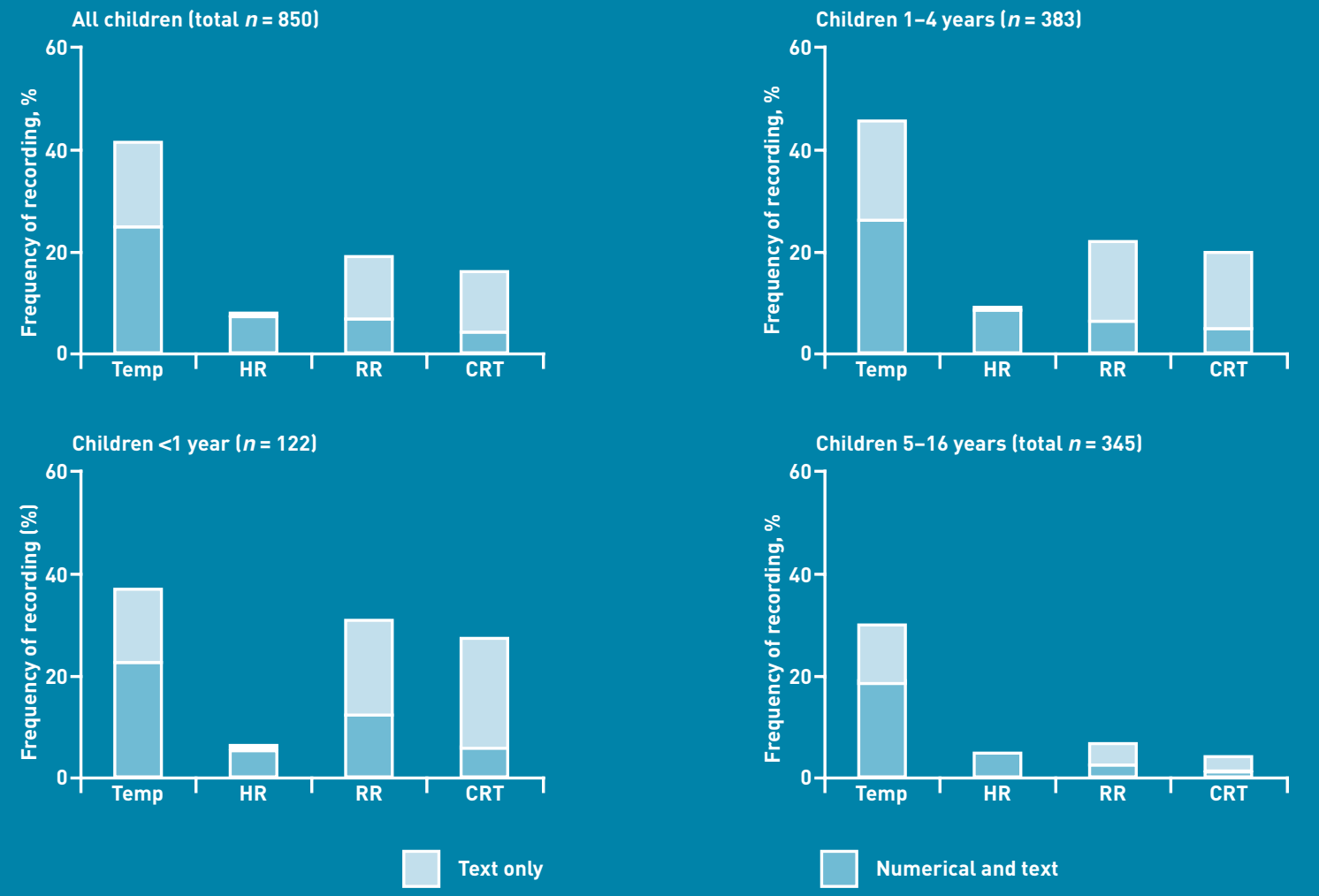

$C R T=$ capillary refill time. $H R=$ heart rate. $R R=$ respiratory rate. Temp $=$ temperature.

Figure 2. Frequency of text recording only relating to vital signs compared to numerically recorded vital signs by GPs. was good (kappa 0.96).

Global assessment was much more frequently documented in infants $(60.7 \%)$, compared to $1-4$ year olds $(43.6 \%)$, compared to $5-16$ year olds (20.9\%) (Figure 3). These differences were significant $k<1$ year olds versus $1-16$ year olds, $P<0.001 ;<5$ year olds versus $5-16$ year olds, $P<0.001)$. Of children with serious infections, global assessment was documented in $30.4 \%$ (7/23), compared to 37\% (306/827).

Those children for whom the GP had specifically documented 'well' (defined as GP documentation of 'well' 'not unwell' or 'not ill' in consultation record, 127/850, $14.9 \%$ ) had significantly higher frequencies of vital signs recording (combined numerical or text recordingl than those children in whom the GP had not documented 'well'. Overall 'well' children were significantly more likely to have at least one vital sign documented by numerical value or text 195/127, 74.8\% versus 365/723, 50.5\%, $P<0.001$ ), which remained significant after age stratification in children $1-4$ years $(P=0.004)$ and $5-16$ years $(P<0.001)$, but not infants. Frequency of individual vital sign recording (combined numerical or text) was significantly higher in 'well' children for temperature $152.8 \%$ versus
$39.0 \%, P=0.004)$, RR $(29.9 \%$ versus $16.6 \%$, $P=0.001)$, and CRT (24.4\% versus $14.4 \%$, $P=0.008)$, however CRT lost significance, and temperature was only significant for 5-16 years and RR for 1-4 years when stratified by age groups. There was no significant difference in recording of HR.

\section{DISCUSSION}

\section{Summary}

This observational study supports existing literature that GPs infrequently record vital signs in children presenting with acute infections in England. ${ }^{8}$ The study had speculated that GPs might use nonnumerical words and phrases to record vital signs rather than numerical values this does appear to be the case, and leads to modest improvement in recording rates when added to numerical recording alone. The study also speculated that GPs might use alternative methods of assessment other than vital signs, for example, global assessment, however while this may be true it was only documented in one-third of children overall.

Apart from temperature, children aged $<5$ years infrequently had vital signs documented, which is at odds with 2007 


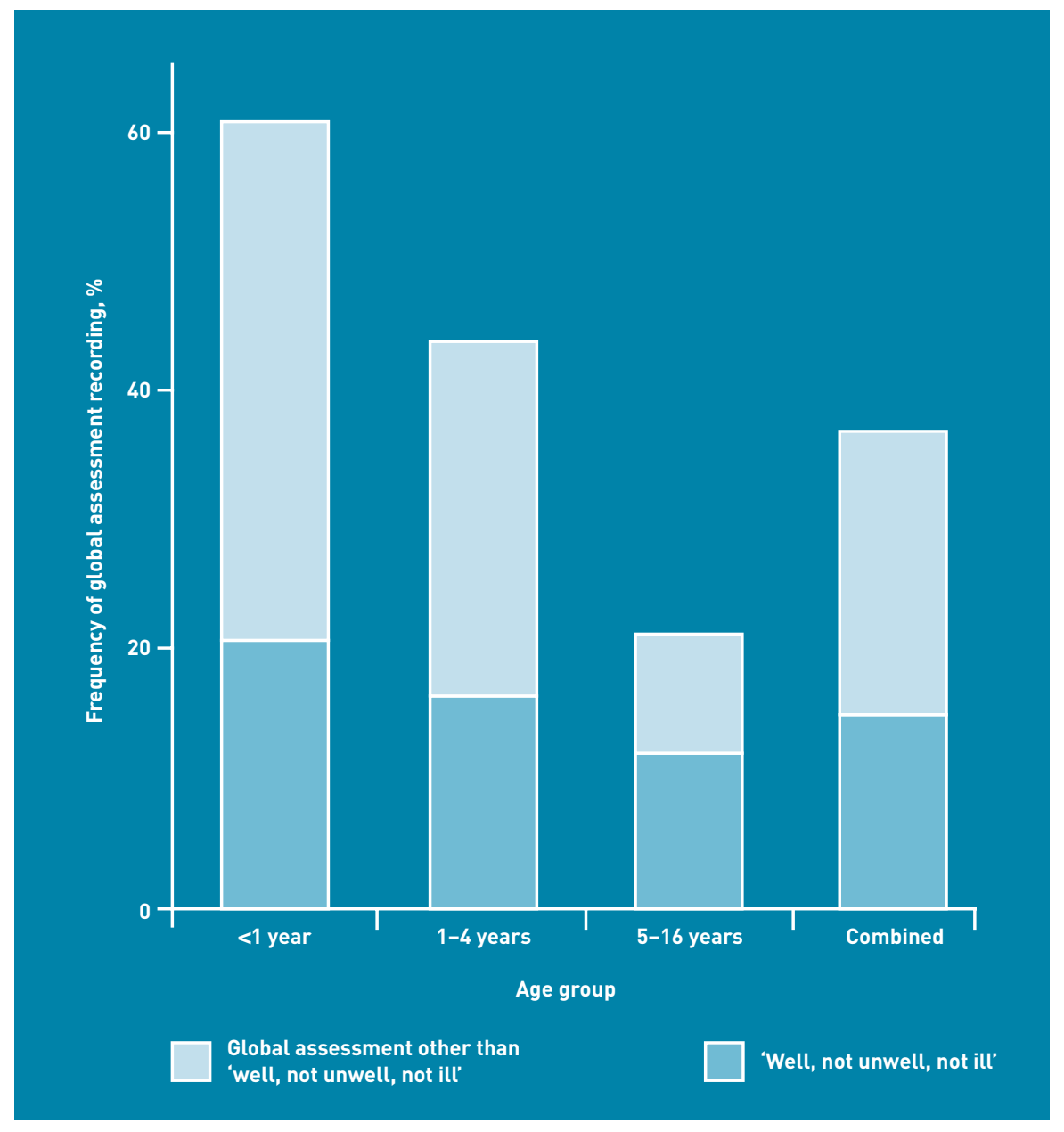

Figure 3. Frequency (\%) of documentation of global assessment by GPs in 850 children with symptoms of acute infection. were measured by GPs but not recorded in the notes, which would underestimate the frequency of vital sign measurement. On the other hand, GPs were aware that the study was being done, which may also have biased results towards more detailed documentation.

The study did not include generic statements such as 'chest clear' in the classification as a text proxy for vital signs, which may have underestimated GP assessment of vital signs. A history or presence of fever was not an inclusion criterion in this analysis, limiting comparability to NICE guidance. The study collected the data from over 100 GPs assessing nearly 1000 children in 15 GP surgeries in two counties in England. These are relatively 'well-doctored' and more rural areas, but these findings are likely to be fairly reflective of UK practice. The study sample included children up to age 16 years, whereas the NICE guidelines for children with feverish illness apply to children younger than 5 years, ${ }^{1}$ however the sample was stratified by age to reflect this. The definition of serious illness was based on referral or admission to hospital rather than final diagnosis. The study was therefore unable to determine the final outcome for these children, however it was considered that a definition of 'serious' based on acute referral or admission to hospital was clinically relevant to GPs.

\section{Comparison with other studies}

The results of this study support the results of a recent survey which found that GPs seldom rely on vital signs, particularly when assessing children who they do not think have a serious infection. ${ }^{8}$ Self-reported thermometer use was also studied among a group of $116 \mathrm{GPs}$, and found that more than half of the GPs reported that they used a thermometer up to only a dozen times over a 6-month period, or not at all. ${ }^{12}$ A baseline audit of triage recording of vital signs in children $<6$ years of age in an emergency department setting in 2007 showed higher levels of recording than in this study..$^{13}$ However even in this emergency setting, vital signs were recorded in variable proportions of children (temperature was recorded in $65 \%$, pulse in $53 \%$, RR in 31\% and CRT in $13 \%$ of 106 children). ${ }^{13}$

\section{Implications for practice and research}

The results confirm that UK GPs do not measure vital signs in many children with acute infections, including those with serious infections. This appears at odds with 2007 NICE clinical guidelines. 


\section{Funding}

The Department of Primary Care Health Sciences is part of the NIHR School of Primary Care Research. Funding for the study was provided by a research grant from the Meningitis Research Foundation Iproject number 0601.0 Improving the early recognition of meningitis and septicaemia in children and adolescents).

\section{Ethical approval}

Oxfordshire Research Ethics Committee (ref: 07/Q1606/12).

\section{Provenance}

Freely submitted; externally peer reviewed.

\section{Competing interests}

The authors have declared no competing interests.

\section{Acknowledgements}

We would like to acknowledge the invaluable assistance of all the parents who completed the questionnaires, as well as GPs and their staff from the participating surgeries in Oxfordshire and Somerset. In particular, we appreciate the assistance and enthusiasm of Dr Lindsay Smith and Research Nurse Calli Smith and the East Somerset Research Consortium. Research Nurse Diane McLeod provided helpful assistance with this study in Oxford, and Professor David Mant provided comments on the draft manuscript. .

\section{Discuss this article}

Contribute and read comments about this article on the Discussion Forum: http://www.rcgp.org.uk/bjgp-discuss
Reasons for this mismatch are unclear. however may include the following possible explanations: GPs might find other methods of assessment more useful, or there might be obstacles to GPs measuring vital signs.

GPs have previously described that the activity or behaviour of a child is more useful in assessing severity of illness than vital signs. ${ }^{8}$ Indeed 'gut feeling' was paramount in a large prospective study among GPs in Belgium; the GP's feeling that 'something was wrong' had the greatest predictive value of serious infection in all classification models. ${ }^{14}$ It is possible that this contributed to why the GPs in this study recorded vital signs infrequently, however in only one-third of consultations were terms and phrases describing global assessment recorded. The basis for GPs' 'gut feeling' is unclear. Although the value of certain global signs to 'rule-out' serious illness has been challenged, ${ }^{15}$ evidence to date suggests "gut feeling' or an overall assessment does have an important positive predictive value ${ }^{14}$ and therefore should be documented in children presenting with acute infections.

Accurate measurement of vital signs is difficult within the constraints of the GP consultation. For example many experts recommend that RR is measured over 1 full minute of counting to reduce variability which is difficult in a short appointment. ${ }^{16,17}$ Variability of $\mathrm{HR}$ and breathing rate increase with agitation of the child, therefore ideally even more time might be needed to obtain stable measures. ${ }^{16}$ The normal reference ranges of vital signs are not always clearly defined, for example the normal range for $H R$ varies with temperature in children with acute self-limiting infections, and there is discrepancy between modelled ranges and those in guidelines. ${ }^{18,19}$ The diagnostic value of vital signs in the low prevalence setting of UK primary care is also uncertain, with most published data from populations with higher prevalence of serious disease, such as emergency departments. ${ }^{3}$ However, the available data from ambulatory settings has shown a high positive predictive value of selected vital signs such as high temperature and tachypnoea for identifying serious illness in children.,4 The absence of data in the primary care setting therefore should provoke data gathering and analysis to inform evidence of the diagnostic value of at least a core set of vital signs. This is even more important given growing pressures for acute appointments both in and out of hours, coupled with ever increasing scrutiny of GP performance and medicolegal pressures. Technological advances in vital signs measurement devices in terms of convenience, accuracy, and connectivity with GPs' electronic record systems may facilitate such research going forward. The existing evidence supports the diagnostic value of global assessment, and we suggest that this also should continue to be assessed and documented during assessments of unwell children.

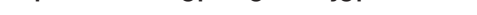




\section{REFERENCES}

1. National Collaborating Centre for Women's and Children's Health. Feverish illness in children: assessment and initial management in children younger than 5 years. Clinical Guideline, May 2007. London: NICE, 2007.http://www.nice.org. uk/nicemedia/live/11010/30525/30525.pdf laccessed 15 Aug 2012).

2. Harnden A. Recognising serious illness in feverish young children in primary care. BMJ 2007; 335(7617): 409-410

3. Van den Bruel A, Haj-Hassan T, Thompson M, et al. Diagnostic value of clinical features at presentation to identify serious infection in children in developed countries: a systematic review. Lancet 2010; 375(9717): 834-845.

4. Mahabee-Gittens EM, Grupp-Phelan J, Brody AS, et al. Identifying children with pneumonia in the emergency department. Clin Pediatr 2005; 44(5): 427-435.

5. Clark JE, Hammal D, Spencer D, Hampton F. Children with pneumonia: how do they present and how are they managed? Arch Dis Child 2007; 92(5): 394-398.

6. Lynch T, Platt R, Gouin S, et al. Can we predict which children with clinically suspected pneumonia will have the presence of focal infiltrates on chest radiographs? Pediatrics 2004; 113(3 Pt 1): e186-e189.

7. Palafox M, Guiscafre $H$, Reyes $H$, et al. Diagnostic value of tachypnoea in pneumonia defined radiologically. Arch Dis Child 2000; 82(1): 41-45

8. Thompson M, Mayon-White R, Harnden A, et al. Using vital signs to assess children with acute infections: a survey of current practice. Br J Gen Pract 2008: 58(549): 236-241.

9. Heneghan C, Glasziou P, Thompson M, et al. Diagnostic strategies used in primary care. BMJ 2009; 338: b1312.
10. Haj-Hassan TA, Thompson MJ, Mayon-White RT, et al. Which early 'red flag symptoms identify children with meningococcal disease in primary care? $\mathrm{Br} J$ Gen Pract 2011; DOI 10.3399/bjgp11X561131.

11. McCarthy PL, Sharpe MR, Spiesel SZ, et al. Observational scales to identify serious illness in febrile children. Pediatrics 1982; 70(5): 802-809.

12. Clarke S. Use of thermometers in general practice. BMJ 1992; 304: 961-963.

13. Bird C, Shea A, Michie CA, George G. A simple intervention improves the recording of vital signs in children presenting to the emergency department. Emerg Med J 2009; 26(10): 698-700.

14. Van den Bruel A, Aertgeerts B, Bruyninckx R, et al. Signs and symptoms for diagnosis of serious infections in children: a prospective study in primary care. Br J Gen Pract 2007; 57(540): 538-546.

15. Bass J, Wittler RR, Weisse ME. Social smile and occult bacteraemia. Ped Infect Dis J 1996; 15(6): 541.

16. Margolis P, Gadomski A. Does this infant have pneumonia? JAMA 1998; 279(4): 308-313.

17. Simoes EAF, Roark R, Berman S, et al. Respiratory rate: measurement of variability over time and accuracy at different counting periods. Arch Dis Child 1991; 66(10): 1199-1203

18. Thompson M, Coad N, Harnden A, et al. How well do vital signs identify children with serious infections in paediatric emergency care? Arch Dis Child 2009; 94(11): 888-893.

19. Flemming S, Thompson M, Stevens R, et al. Normal ranges of heart rate and respiratory rate in children from birth to 18 years of age: a systematic review of observational studies. Lancet 2011; 377(9770): 1011-1118. 


\section{Appendix 1. Included and excluded text used by GPs as proxies for vital signs.}

\begin{tabular}{|c|c|c|c|c|}
\hline & Temperature & Heart rate & Respiratory rate & Capillary refill time \\
\hline $\begin{array}{l}\text { Included text: } \\
\text { positive and } \\
\text { negative included }\end{array}$ & $\begin{array}{l}\text { Febrile/pyrexial } \\
\text { Fever/temperature } \\
\text { Hot/warm }\end{array}$ & $\begin{array}{l}\text { Pulse normal/not raised } \\
\text { HR increased }\end{array}$ & $\begin{array}{l}\text { Respiratory effort } \\
\text { Work of breathing } \\
\text { Respiratory rate } \\
\text { Dyspnoea } \\
\text { Recession/flaring chest } \\
\text { Respiratory distress } \\
\text { Tachypnoea } \\
\text { RR normal }\end{array}$ & $\begin{array}{l}\text { BP 107/66 } \\
\text { Hydrate/perfused } \\
\text { Moist } \\
\text { Cap refill normal } \\
\text { Warm/cold hand/peripheries } \\
\text { No dehydration/not dry } \\
\text { Some mottling } \\
\text { Skin turgor OK } \\
\text { No cyanosis } \\
\text { Normal/good colour } \\
\text { Pale }\end{array}$ \\
\hline $\begin{array}{l}\text { Excluded text: } \\
\text { (examples given) }\end{array}$ & $\begin{array}{l}\text { No temperature } \\
\text { symptoms }\end{array}$ & $\begin{array}{l}\text { HS normal/NAD } \\
\text { HS 1+2 } \\
\text { Systolic murmur }\end{array}$ & $\begin{array}{l}\text { General observation: (Chest/ } \\
\text { respiratory system clear/ } \\
\text { OK/NAD/normal/nil acute) } \\
\text { Chest: (chesty/croupy) } \\
\text { Air entry: (good/full/bilate AE) } \\
\text { Percussion: (PN resonant) } \\
\text { Transmitted sounds: } \\
\text { (transmitted sounds from throat) } \\
\text { Added sounds: (wheeze/ } \\
\text { crepitations/crackles) }\end{array}$ & $\begin{array}{l}\text { Flushed } \\
\text { Wet and dirty nappies } \\
\text { High colour }\end{array}$ \\
\hline
\end{tabular}

\section{Appendix 2. Global assessment words and phrases used by GPs.}

\begin{tabular}{|c|c|c|c|}
\hline (Code) group & $\begin{array}{l}\text { Phrases used } \\
\text { traffic light system }\end{array}$ & $\begin{array}{l}\text { Phrases used } \\
\text { Yale Observation Scale }\end{array}$ & Phrases used by GPs \\
\hline (1) Quality of cry & $\begin{array}{l}\text { Strong, normal cry/not crying }(G) \\
\text { Weak, high pitched, or continuous } \\
\text { cry (R) }\end{array}$ & $\begin{array}{l}\text { Strong or none (1) } \\
\text { Whimper or sob (3) } \\
\text { Weak or moaning, high pitched, } \\
\text { continuous cry, or hardly responds (5) }\end{array}$ & $\begin{array}{l}\text { No cry, crying, crying +++ } \\
\text { Grizzly } \\
\text { Screaming } \\
\text { Chatty }\end{array}$ \\
\hline (2) Alertness & $\begin{array}{l}\text { Stays awake or awakens quickly }(G) \\
\text { Wakes only with prolonged stimulation (A) } \\
\text { Decreased activity (A) } \\
\text { Does not wake, or if roused does not } \\
\text { stay awake (R) }\end{array}$ & $\begin{array}{l}\text { If stays awake, or if asleep wakens } \\
\text { quickly (1) } \\
\text { Eyes close briefly when awake or } \\
\text { awakens with prolonged stimulation (3) } \\
\text { No arousal and falls asleep (5) }\end{array}$ & $\begin{array}{l}\text { Alert, responsive, lively } \\
\text { Active, running around room } \\
\text { Bright } \\
\text { Asleep until undressed, slept through exam } \\
\text { Fast asleep, looks tired }\end{array}$ \\
\hline $\begin{array}{l}\text { (3) Response to } \\
\text { parent or stimulation }\end{array}$ & $\begin{array}{l}(G) \text { Abnormal response }(A) \\
\text { No response }(R) \\
\text { Smiles/content }(G) \\
\text { No smile }(A)\end{array}$ & $\begin{array}{l}\text { Cries brief or no cry and content (1) } \\
\text { Cries on and off (3) } \\
\text { Persistent cry with little response (5) } \\
\text { Smiles or alerts (consistently) (1) } \\
\text { Brief smile or alert (3) } \\
\text { No smile, anxious, dull; no alerting to } \\
\text { social overtures (5) }\end{array}$ & $\begin{array}{l}\text { Happy, smiling, not distressed } \\
\text { Interested, playing with toys } \\
\text { Content, not irritable, settled, cheerful } \\
\text { Cooperative, relaxed happy child, } \\
\text { Happy until examined, sociable } \\
\text { Quiet, miserable, unsettled } \\
\text { Tearful, distressed, reluctant to let doctor look } \\
\text { Cuddling dad, subdued, uncooperative, grumpy } \\
\text { Very quiet, very cross } \\
\text { Resisting examination, clingy, run down }\end{array}$ \\
\hline (4) 'Gut feeling' & Appears ill to a healthcare professional (R) & & $\begin{array}{l}\text { Well, not too ill } \\
\text { Does not look acutely unwell } \\
\text { No adverse features, not toxic } \\
\text { General condition OK } \\
\text { Looks peaky, unwell }\end{array}$ \\
\hline (5) Tone & & & $\begin{array}{l}\text { Handles well, good tone } \\
\text { Fights well } \\
\text { Walking independently }\end{array}$ \\
\hline
\end{tabular}

